\title{
Historical industrialisation, path dependence and contemporary culture: the lasting imprint of economic heritage on local communities
}

\author{
Robert Huggins (D) *, , Michael Stuetzer*****, Martin Obschonka**** \\ and Piers Thompson***** \\ *School of Geography and Planning, Cardiff University, Cardiff, UK \\ **Baden Wuerttemberg Cooperative State University, Mannheim, Germany \\ ***Faculty of Economic Sciences and Media, Institute of Economics, Ilmenau University of Technology, \\ Ilmenau, Germany \\ ****Australian Centre for Entrepreneurship Research, Queensland University of Technology, Brisbane, \\ Queensland, Australia \\ ***** Nottingham Business School, Nottingham Trent University, Nottingham, UK \\ ${ }^{\dagger}$ Correspondence to: email <HugginsR@cardiff.ac.uk>
}

\begin{abstract}
Culture matters for regional economic development and is one source of cognitive lock-in that influences path creation and dependency. However, little is known about the sources of regional variation in culture. This study explores the long-term imprinting effect of the Industrial Revolution on cultural practices across local communities in Great Britain. Historical data from 1891 on the employment in large-scale industries (e.g. textiles and steel) is used to estimate causal effects of industrialisation on five cultural dimensions. It is found that historical industrialisation is still reflected in contemporary local cultures marked by lower engagement with education and employment, less adherence to social rules but stronger collective action and social cohesion. It is concluded that one reason for the relatively poor effect of the public policies on local and regional economic development is that historical industrialisation has left a lasting legacy on contemporary culture in many places that impairs institutional efforts to foster change.
\end{abstract}

Keywords: Cultural evolution, community culture, industry structure, industrialisation

JEL classifications: $\mathrm{O} 1, \mathrm{O} 14, \mathrm{O} 43$

Date submitted: 27 August 2018 Editorial decision: 24 February 2021 Date Accepted: 1 March 2021

\section{Introduction}

Communities, regions and nations differ in their culture (e.g. Hofstede, 1980; Tabellini, 2010; Obschonka et al., 2018; Huggins and Thompson, 2021). Such culture is often defined as the collective programming of the mind, distinguishing one group from another, and refers to beliefs and values that are transmitted within groups over generations (Guiso et al., 2006). The scholarly interest in culture has recently been spurred on by an increasing number of studies that find cultural dimensions to be an important driver of economic processes and performance (e.g. Greif, 1994; Guiso et al, 2006; Tabellini, 2010; Stuetzer et al., 2018). For old industrial areas, this culture may affect the potential to create or renew development paths, rather than simply extend existing ones until they are exhausted 
(Hassink, 2010; Hu and Hassink, 2016). This is likely to be driven by the cognitive lockin that culture can generate (Blažek et al., 2020). However, there is only a small stream of literature that has tried to capture the sources of such cultural differences (Inglehart and Baker, 2000; Tabellini, 2010; Nunn and Wantchekon, 2011). One reason for this lack of research on the determinants of cultural differences is endogeneity: culture affects economic outcomes which in turn affects culture (Guiso et al., 2006). Another reason is that culture is changing very slowly making it difficult to non-arbitrarily select a starting point in time.

The present article addresses both challenges. We focus on the effect of industrialisation on cultural differences across communities in Great Britain. The Industrial Revolution was a major watershed in socio-economic history transforming production, work, classstructures, lifestyles, urbanisation, etc. In the case of countries such as Great Britain, the Netherlands and the USA, the Industrial Revolution was uneven across their sub-national territories (Zijdeman, 2009; Glaeser et al., 2015). The emergence of large-scale production in industries such as steel and textiles largely depended on the availability of nearby cheap coal as an energy source (e.g. Stuetzer et al., 2016).

The aim of this article is to investigate whether present-day differences in culture across British communities are a result of previous large-scale industry and industrialisation (Stuetzer et al., 2016; Obschonka et al., 2018; Stuetzer et al., 2018). The study considers how industrialisation may initiate the evolutionary processes involved in the formation of cultural practices within localities, which lead to particular networks forming that have implications for the future economic development of the localities. It builds upon recent contributions in economic geography that have taken a Bordieusian view of culture, focussing on practices in terms of the actions employed by local agents as part of the way they undertake their daily lives (Spigel, 2017). Current community cultural practice is captured using the measures developed by Huggins and Thompson (2016). This approach has the benefit of measuring culture at a more localised level, which is critical given the very distinct and spatially concentrated patterns of historical industrialisation. It also distinguishes between several dimensions of community cultural practice, recognising that major historical events do not necessarily lead to 'modernisation' across all sets of values that form prevailing community cultures (Inglehart and Baker, 2000).

This article differs from previous work by, for example, Huggins and Thompson (2016), which explores the effects of different dimensions of culture, but instead investigates its determinants. Given the long-term role culture is suggested to play in determining the extent and nature of development experienced (Blažek et al., 2020), our study seeks to provide more insight into the events and forces that have left a lasting imprint on old industrial areas, in particular in terms of constraining and limiting their development paths (Hassink, 2010). Understanding these constraints not only provides an understanding of the processes that have left these areas lagging the more advanced regions in their nations, but a more culturally contextualised perspective of the economic evolution of regions.

The remainder of the article is structured as follows. Section 2 reflects on the existing literature that has considered local and regional development, in particular contributions that have considered the role culture may play in processes of path dependence and lockin. This critical analysis is used to hypothesise how differing community cultural practices may emerge and persist. Section 3 introduces data and the methods of analysis used to test the hypotheses. The results are presented in section 4 . Section 5 summarises and concludes the study. 


\section{Regional development paths: culture's role and genesis}

Although there have been numerous policy interventions targeting the reduction of regional inequalities within and across countries, there is growing discontent with their success (Rodríguez-Pose, 2018). Evolutionary economic geography suggests that one of the difficulties for old industrial areas is the potential for path dependence and lock-in to limit the regional development paths available (Hassink, 2010; Coenen et al., 2015). This study is focussed on one determinant of this path dependence often associated with institutional economic geography, i.e. the prevailing culture (Hudson, 1994; Cooke and Rehfeld, 2011).

While studies have noted the role of technological and functional lock-in and specialisation in path dependence, others have suggested that factors beyond these can play a role, including economic, political, ideological and cultural layers of history (Massey, 1984). Some scholars have highlighted the role of what they term industrial culture or manufacturing culture, which some consider to be industry-specific (Gertler, 2004; Cooke and Rehfeld, 2011), while others describe it as a place-based phenomenon (Görmar and Harfst, 2019). Depending on how strongly businesses are embedded and engaged with regional actors, industrial and regional culture influence one another (Cooke and Rehfeld, 2011; Becattini, 2015). This suggests that industrial culture is embedded in wider social interactions, characteristics and lifestyles (Görmar and Harfst, 2019), potentially making regional and industrial culture hard to separate. Furthermore, regional culture also plays a key role in the way resources can be mobilised in regional economies to adapt to external shocks and slower structural changes (Hu and Hassink, 2016; MacKinnon et al., 2019).

In summary, the scholarly literature recognizes that culture influences the extent to which path dependence, exhaustion, renewal and creation can occur. It also shows that industry activities and industry culture also affect the wider social conditions and community culture present. However, the literature that investigates the flow from industrial activities to the formation, persistence or evolution of culture is noted in the regional development literature, but it is not strongly developed or formulated.

\subsection{Defining community cultural practices and their persistence}

Culture has been defined and described in a number of ways. Acknowledging the importance of different scales (Hassink and Gong, 2017), it is universally considered to be held at the group rather than individual level, but can influence individual's decisions. Hofstede (1980) referred to it as the 'collective programming of the mind'. Guiso et al. $(2006,23)$ describe culture as 'those customary beliefs and values that ethnic, religious, and social groups transmit fairly unchanged from generation to generation'. One powerful transmission channel is socialisation where parents pass on particular beliefs and attitudes to their children (Alesina and Giuliano, 2015). However, the selective migration of individuals with specific attitudes and beliefs to regions with populations with matching attitudes and beliefs is also a source of cultural persistence (Jokela, 2009).

In this article, we focus on community culture. In terms of the community element, this refers to societal groupings. In reality, these groupings may, or may not, be place-based (Storper 2008), but within this study we define community culture as social values and norms held by groups that are largely place-based. Community culture, therefore, relates to the social structure and features of group life within localities. These are generally considered to be beyond, but not isolated from, the economic life of such places. In essence, 
community culture consists of the overarching or dominant mindsets that underlie the way in which localities function, i.e. the ways and means by which individuals and groups within communities interact and shape their environment.

A number of approaches have been utilised to measure national, regional and local culture. Some of the approaches used have been data driven (e.g. Hofstede, 1980). These approaches have been criticised for not reflecting the whole population (McSweeney, 2002), or relating to only a subset of values associated with work (Kaasa et al., 2013). These may be viewed as criticisms of others utilising Hofstede's (1980) work in areas for which it was never intended, rather than direct criticisms of the schema. Others have adopted a more theory-based approach as is the case with Inglehart's (1971) modernisation theory. Often these have utilised survey data to measure community culture. These approaches tend to initially capture values at the individual level and subsequently aggregate them to a higher spatial level. However, it is disputed whether or not the aggregation of individually held values, beliefs and norms reflects the group-held culture (McSweeney, 2002). It is also possible to produce regional measures of culture from data drawn from sources such as the European Social Survey and European Values Survey (Kaasa et al., 2013). However, this involves the use of multiple waves and further disaggregation to the local level is not achievable.

To overcome such limitations, Huggins and Thompson (2016) utilise an approach drawing on existing theories and associated measures of community culture, but capturing them through secondary data. Although this allows a more localised measure of community culture to be produced, the potential limitation is that culture is less directly captured, but through activities associated with particular cultures. Reflecting this indirect measurement, we refer to these as community cultural practices to distinguish them from the unobserved community cultural beliefs and values (Spigel, 2017). Such a focus on practices is not unprecedented in cultural research, with, for example, the GLOBE study of cultural dimensions at the national level drawing on measures of cultural practices (House et al., 2004). Cultural practices are thereby understood as 'descriptive norms providing information on the typical behaviors of most people in a culture' (Stephan and Pathak, 2016, 511).

In terms of historical industrialisation, the production of goods in economies such as the UK and others displays a strong spatial concentration associated with the coal deposits providing the source of energy that allows large-scale production (Glaeser et al., 2015). This means that when investigating the lasting impact of this industrialisation on community culture a more disaggregated measure is required, so Huggins and Thompson's (2016) five dimensions of community cultural practice as outlined in Figure 1 are utilised. Each of the five dimensions utilised is drawn from the existing studies, allowing different aspects of community cultural practice to be examined. The five dimensions are presented below along with their importance for regional development and path creation or dependency, and we theorise on how industrialisation has left an imprint on each dimension of community cultural practice. We consider potential mechanisms associated with their evolution including: social mobility; selective migration; local economic hangovers; working conditions; unionisation; and desires for redistribution. As a whole, it is argued that prevailing community cultural practices can be one of the factors that influence the development opportunities available, and the hypotheses established are summarised in Figure 1. 


\begin{tabular}{|c|c|c|}
\hline $\begin{array}{c}\text { Dimension of Community } \\
\text { Culture Practice }\end{array}$ & $\begin{array}{c}\text { Mechanisms Relating Historical } \\
\text { Industrialisation to Culture }\end{array}$ & $\begin{array}{c}\text { Hypothesised } \\
\text { Relationship }\end{array}$ \\
\hline $\begin{array}{c}\text { Embracement of Education } \\
\text { and Employment }\end{array}$ & Limited social mobility & Negative \\
\hline Social Cohesion & Selective migration & Positive \\
\hline $\begin{array}{c}\text { Feminine and Caring } \\
\text { Activities }\end{array}$ & $\begin{array}{c}\text { Economic systems separating employment } \\
\text { and household activities }\end{array}$ & Positive \\
\hline Adherence to Social Norms & $\begin{array}{r}\text { Repetitive, stressful working practices, } \\
\text { Economic hardship }\end{array}$ & Negative \\
\hline Collective Action & Desires for redistribution, & Positive \\
\hline
\end{tabular}

Figure 1. Mechanisms linking historical industrialisation to community cultural practices.

\subsection{Engagement with education and employment}

Engagement with education and employment captures an underlying work ethic (Weber, 1905; Becker and Woessmann, 2009) and orientation towards longer term planning for work (Hofstede, 2001; Tabellini 2010). This dimension relates to the extent to which individuals place a strong emphasis on self-sufficiency and making a contribution to society (Becker and Woessmann 2009). Such a dimension is related to human capital and absorptive capacity for path creation, along with the foresight to avoid simple path extension and eventually exhaustion.

The concept of 'engagement with employment and education' draws on work ethic, long-term planning and self-sufficiency (Becker and Woessmann, 2009; Tabellini 2010). Industrialisation may play a role in developing and perpetuating particular values by influencing the opportunities and rewards associated with these activities. For example, Flanagan (1982) proposes a perspective based view concerning functional constraints, whereby society chooses behaviours that are the most appropriate and rewarded given the socio-economic context. As industrialisation has been suggested to provide opportunities for greater social mobility compared to previous feudal systems and agriculturally based economies, greater work ethic and societal contribution should be rewarded (Fukumoto and Grusky, 1993). Others, however, have not found large increases in social mobility compared to prior periods, and in the case of the Dutch province of Zeeland social mobility was restricted rather than promoted by industrialisation (Zijdeman, 2009).

Where historical development is associated with large-scale industry there may be increased power distance (Hofstede, 2001), with upper and working classes becoming more segregated. Increasing power distance can contribute to the paternalistic nature of employment and labour relations, which has been observed in old industrial areas (Hudson, 1994). This paternalism can evolve into a culture of dependency initially from the work provided by large-scale employers, but then after structural change by the state (Hudson, 2005). This can allow a form of learned helplessness to be created and as noted by studies such as Matthews and Gallo (2011) and Obschonka et al. (2017), poor economic conditions and limited socioeconomic positions may have impact on cognitive, psychological and social functioning and the ability to deal with their restricted position. If an 
individual's own problems are likely to be attributed to external factors, solutions to these problems are naturally considered to come from the outside too.

An additional detrimental effect of the working conditions in communities supported by large-scale industries is the dominance of unskilled occupations. As most jobs required little to no education, the incentives to acquire education remain low, which can result in reduced educational investments (Gylfason, 2001).

Summing up, this section has shown that the nature of large-scale industrialisation limits social mobility and generates a reliance on others, which means that the rewards associated with work ethic and investments in education will be reduced:

H1: In localities where large-scale industry was more important, contemporary community culture will display lower levels of engagement with education and employment.

\subsection{Social cohesion}

Social cohesion incorporates measures of homogeneity in terms of ethnic similarity and religious similarity (Durkheim, 1893; Rodríguez-Pose and Hardy, 2015). This dimension relates to Durkheim's (1893) notion of 'mechanical' and 'organic' solidarity social cohesion, whereby trait similarities and interdependence amongst individuals result in a perceived unity, togetherness and less likelihood of exclusion. This cohesion or otherwise has important consequences for the trust formed and can lead to isolation from outside perspectives (Kwon and Adler, 2014). Social cohesion, therefore, has a strong role in determining social and economic behaviour (Rodríguez-Pose, 2001).

Social cohesion can be influenced both by the working and living conditions present in an area, but also from those who migrate into the area (Huggins and Thompson, 2016). First, working conditions may strengthen social cohesion in communities. For example, work in the factories and mines of industrialising regions was physically demanding and potentially dangerous, which may have created a sense of togetherness. Sometimes paternalistic firm owners even assisted to create this togetherness as an element of social control by providing social benefits, such as housing or medical care (Thompson, 2008). Working men's clubs and sport activities like rowing also shaped togetherness and cohesion among the working class in the industrialised regions (Tranter, 1988).

It has been shown that historical factors can lead to self-selecting migration patterns whereby particular personality traits are reinforced on an on-going basis (Obschonka et al., 2017). In the case of the indirect link between industrial development and community cultural practice, large-scale industry can clearly play a role. Obschonka et al. (2017) outline how those attracted to industrialising areas often came from rural and other peripheral regions out of necessity rather than choice. When the industrial regions began to decline, the less resilient and more passive and pessimistic individuals were more likely to remain, resulting in a less geographically mobile population (Obschonka et al., 2017). This stability in the population along with the personality traits present allows for stronger bonding ties to form, but may restrict the formation of bridging ties to the outside world. The theories relating to selective migration, in particular, suggest that historical industrialisation attracts and retains particular individuals who perpetuate a more socially cohesive externally exclusive culture.

H2: In localities where large scale industry was more important, contemporary community culture will be more socially cohesive. 


\subsection{Feminine and caring activities}

The cultural dimension of feminine and caring activities reflects the social norms and expectations developed in relation to the social and work roles of each gender and where differing domains may take precedence (Hofstede, 2001; House et al., 2004; Carter et al., 2012). Masculine cultures are considered to be more competitive and materialistic than their feminine counterparts, which are more caring and harmonious in their outlook (Hofstede, 1980). Although to some extent this account could be considered stereotypically outdated, the idea of cultural femininity endures (Shneor et al. 2013). Expectations might be that more feminine cultures seek to maintain or protect existing regional institutions rather than seeking new development paths.

There are several lines of argument concerning how industrialisation and the presence of large-scale industries effect the cultural dimension of feminine and caring activities. Earlier modernisation theory suggests that there will be a move towards particular values, promoting amongst others, more equal gender values (Weiner, 1966). However, this is more closely associated with a move to post-industrialism and employment in the services sector rather than the historical industrialisation associated with large-scale production (Inglehart and Baker, 2000).

A key factor relating to community cultural practices concerns the working and living conditions in regions with large-scale industries. Physically arduous conditions - frequently centred around the production of physical goods - have a lasting impact on what inhabitants of old industrial areas regard as work (Hudson, 1994). There is often a highly gendered aspect to this work and the roles taken in society, which again can persist, and is described by Duncan and Smith $(2002,489)$ as a 'local economic hangover'. Therefore, industrialisation in developed economies may be associated with promoting masculine work (Hudson, 1994) and orientations (Spence and Helmreich, 1978). Moreover, a parent's working conditions and experiences can also affect the raising of offspring, mainly through transmitting values in the early formative years of children (Luster et al., 1989). Histories of male orientated manual labour can result in a stronger dimension of feminine and caring activities through imposing a home-based and family orientated role on women (Sackmann and Häussermann, 1994).

Care is needed in interpreting these value transmission mechanisms, with some local economies historically dominated by textile industries having relatively high levels of female economic participation compared with other localities (Glucksmann, 2000). As Sackmann and Häussermann (1994) stress, any regional economic analysis should consider the fine details relating to the different gendered organisation of work and home roles across regions. This is undoubtedly true, but given the general role of historical industrialisation in separating the home and gainful employment, we tentatively suggest a positive link between large-scale industry and the feminine and caring activities cultural dimensions:

H3: In localities where large-scale industry was more important, contemporary community culture will place a greater importance on feminine and caring activities.

\subsection{Adherence to social rules}

Adherence to social rules captures how social conventions, reinforced by reputational effects, are often required as coordination tools for maintaining accepted social norms (Rodríguez-Pose and Storper, 2006; Lorenzen, 2007). This enforcement of social rules 
ensures that subversive activities do not become acceptable and seen as the 'new' social norm. For development through path renewal and creation, these social conventions and reputation are regarded as important coordination tools for information gathering activities (Lorenzen, 2007). However, entrepreneurship may be strengthened where bending lesser rules or norms is permitted.

From the perspective of industrialisation, Marx (1859) developed the 'being determines consciousness' principle, which refers to the effect of working conditions on the thinking and identity of the workforce, with the so-called 'long-arm of the job' shaping cultural attitudes. Adam Smith $(1776,850)$ noted that the division of labour comes with detrimental psychosocial effects for workers, such as ignorance, inability in judging, and the expense of virtues. During the Industrial Revolution, the increasing division of labour was driven by technological change, and the availability of coal-based energy greatly influenced the organisational routines of firms. Instead of many smaller producers relying on specialised artisans, the new mode of production in larger-scale factories relied on low-skilled and labourintensive work consisting of often highly repetitive tasks (Acemoglu, 2002). This repetitive unskilled nature of large-scale production and associated poor working conditions may affect adherence to social rules in a number of regards. Kohn and Schooler (1982) find evidence that more routine and closely monitored work can limit individuals' self-direction, which can lead to reduced adherence to social rules. This may have a generational influence where such attitudes and approaches are brought into parenting and found to lead to higher levels of anti-social behaviour in children as they grow up (Whitbeck et al., 1997).

Declines in appropriate behaviour and standards after industrialisation are linked by some to the dissolution of previous methods of social control through family, patronage and deference, and the church (especially before the development of new formalised institutions such as the police and local authorities), as well as those developed by the working classes themselves (Thompson, 1981). The decline in traditional industries may then remove any paternalistic role played by the large-scale employers noted above (Thompson, 2008), and lead to economic deprivation, which is associated with criminal activities (Power et al., 2010), and decreasing trust (Alesina and La Ferra, 2000). In addition, economic hardship is also found by Whitbeck et al. (1997) to influence parenting behaviours towards more authoritarian sub-optimal approaches. Based on the above we hypothesise the following relationship:

H4: In localities where large-scale industry was more important, contemporary community culture will display lower rates of adherence to the social rules accepted by wider society.

\subsection{Collective action}

Collective action can create greater trust within groups, but any 'aggressive' tendencies must usually be directed outwards at other groups (Greif, 1994; Casson, 1995). This means that collective activities may be associated with a desire for equality, greater equity, social justice, and cooperatively working for the in-group's interests rather than for those of the individual or their family (Hofstede, 1980; Triandis, 1993). In terms of creating opportunities for path creation, more collective community action may weaken the link between entrepreneurial self-efficacy and entry, but suppress the negative effect of the fear of failure (Wennberg et al., 2013).

With particular regard to industrialisation, the shift to an economy based on steam power altered the balance of power between landowners in general, and those with access 
to coal resources, capitalist investors, and labour (Piketty, 2014). Arguments relating to how this wealth and utility should be (re)distributed, and collective action to work towards this, may have left a considerable cultural imprint in those areas that grew rich on these coal reserves (Piketty, 1995). Furthermore, mineral resources and industrial employment may be associated with wider spatial identity, especially beliefs relating to how economic activities should be organised.

In particular, there is a lively debate as to whether or not the presence of mineral resources increases or decreases the populace's preferences for redistribution (e.g. Di Tella et al., 2010; Couttenier and Sangier, 2015). Couttenier and Sangier (2015) find that US states with an above median number of mineral mines are more likely to be against the redistribution of wealth. This may reflect mineral resources resulting in income increases and an important role being played by physical effort in a labour intensive industry, both of which are negatively associated with the desire for redistribution (Piketty, 1995; Couttenier and Sangier, 2015). However, Di Tella et al. (2010) find that if income from oil resources depends more on luck (e.g. rising oil prices) than on effort, people in the USA prefer more redistribution and government action. Where income and wealth are considered to be received 'unfairly', such as the inheritance of land ownership, rather than effort or talent, preferences for taxing and redistributing these 'unfairly high incomes and wealth' are greater (Alesina and Angeletos, 2005).

A further mechanism associated with ensuring better conditions and the fair distribution of rewards is unionisation (Holmes, 2006). Although some unions have origins in clubs and friendly societies formed with the demise of the earlier guild system, the formation of new 'unions' and the expansion of existing ones accelerated with mechanisation (Aldcroft and Oliver, 2017). Unionisation outside the skilled trades gathered pace where large-scale production concentrated labour, allowing effective combination particularly in the coal, metals, engineering and shipbuilding, and textiles industries, resulting in both a geographical and industrial concentration (Aldcroft and Oliver, 2017).

In terms of collective action, trade unions are obvious examples of where individuals work cooperatively for the in-group's interests, where this in-group may be fellow employees or the wider community (Triandis, 1993; Sadler and Thompson, 2001). Trade unions may be restricted to one trade (e.g. mining workers), but a number of possible mechanisms exist that may allow unionisation to be transmitted to other sectors, and union members may move to other sectors (Hester and Fuller, 2001). They may also promote unionisation through their children who work in other sectors, and equally, unions may actively look to spread their influence to other localities and regions (Holmes, 2006). With regard to the UK steel industry, Sadler and Thompson (2001) provide an example of a case whereby industrial unions seek membership from the wider community when they face falling employment of the workers in the traditional industries they represent,

In general, it can be hypothesised that historical large-scale production is associated with the generation of trade unions, which influences the wider community culture in terms of favouring collectivity:

H5: In localities where large-scale industry was more important, contemporary community culture will continue to favour collective activities. 


\section{Data and methods}

To empirically investigate the hypotheses developed above, the study undertakes an analysis using a combination of historical and contemporary data. Recognising that there are considerable local variations in both industrial development and community culture (Huggins and Thompson, 2016; Stuetzer et al., 2016), the analysis is undertaken using Local Authority Districts (LADs) covering Great Britain. We excluded two LADs that are both geographically smaller and have extremely low residential populations (Isles of Scilly and City of London), because many contemporary control variables are not available for them. This provides us with 378 non-overlapping localities. Ideally, the localities would be based on functional economic activity patterns, but unfortunately the majority of the available data are recorded based on administrative divisions. The remainder of this section outlines the community cultural dimensions to be investigated, the historical and contemporary measures used to capture industrialisation and other controls, and the estimation procedure used to overcome issues of endogeneity. Table 1 provides an overview of the variables and their sources and the correlation matrix and the descriptive statistics of all variables are presented in Table 1. For the regressions, all non-binary and non-ordinal variables were logged (Table 2).

\subsection{Community cultural practice variables}

The community cultural practice measures are based on those used by Huggins and Thompson (2016), which are indicators developed using secondary data to create the five dimensions of community cultural practice outlined above. Importantly, they are based on secondary data sources informed by empirical studies of culture that have concentrated on particular aspects of community culture, such as social capital, which allow a local spatial perspective to be taken. Due to space constraints, we only provide a short description of the measurement of these dimensions and refer to Huggins and Thompson (2016) for details of the empirical implementation. The data for the five community cultural practice dimensions are from 2010 and 2011 and draw upon sources such as the national census and labour surveys as outlined in Table 1.

\subsection{Historical industry structure during the Industrial Revolution}

To capture historical patterns of industrialisation, data for 1891 relating to the employment structure of localities are utilised. The data used here are drawn from the British Census and focuses on large-scale industries. Large-scale employers were largely associated with the use of steam power (Crafts and Mulatu, 2005; Crafts and Wolf, 2014). Coal-based industries are defined as the three industries that most heavily used coal for combustion in steam engines - metal manufacturers, textiles and bricks and pottery (see Table 1 for detailed information on the industry characteristics). Supplementary Appendix Table A1 indicates that these industries were large-scale - textiles ranks second out of 15 industries in average plant size and metal manufacturing ranks fourth. Steam power allowed these industries to be among the first to adopt the factory system and the assembly line, leading to large economies of scale. A fourth industry included as a measure of large-scale employment is coal mining (Glaeser et al., 2015). Note that these large-scale industries also rank at the bottom in the use of white-collar employment. These data on the number of employees in each occupation are available at the historical registration district levels in 
Table 1. Regression variables and their sources

Variable

Description and Source

Distance from Coalfield before 1700

Distance of the border of a county to the border of the nearest coalfield before 1700 in kilometre

Employment Share Large-Scale Industries in 1891

Engagement with Education and Employment for 2010

Social Cohesion for 2010

Digitized historic map from Hatcher (1993)

Employment share in large-scale industries (coal mining, metal manufacturers, textiles, bricks and pottery) in 1891. The employment data come from the British Census in 1891

Engagement with education and employment incorporates male economic activity rates from the 2010 Annual Population Survey (APS) to capture an underlying work ethic. Educational engagement is captured using the inverse of the proportion of the population with no education (APS) and days of absenteeism at primary and secondary schools in 2009 to reflect the community approach to education (Schools' Statistics)

Social cohesion incorporates measures of homogeneity in terms of ethnic similarity and religious similarity in 2011 (Census data). Inflows into the community are captured by gross migration in 2010 (National Health Service Central Register) and the proportion of the population born abroad in 2010 (APS). Connection to the country is also captured through those perceiving themselves to be of the nationality of the resident country (e.g. English in English localities)

Feminine and Caring for 2010

Feminine and caring activities measures opportunities for female employment (female economic activity and the proportion of female employment which is part-time, both from the 2010 APS), and caring activities undertaken that are unpaid in 2011 (Census)

Adherence to Social Rules for 2010

Adherence to social rules takes the inverse of measures of rule (formal and informal) breaking including: age accounted for alcohol related deaths in the period from 1998 to 2004 and younger age conceptions in 2009 (both from Health Statistics Quarterly), and crimes committed in terms of non-sexual violent crimes and crimes by deception in 2009 (Notifiable crimes recorded by the police)

Collective Action for 2010

Collective action is captured directly by trade union membership in 2010 (APS) and indirectly through preferences for left of centre policies in terms of the proportion voting for parties with these leanings in 2010 (Electoral Commission)

Watermills around 1800

Number of watermills around 1800 .

Source: Kanefsky (1979)

Distance-weighted sum of the employment levels of all other regions

Source: Own computations based on the 1891 employment data

Dummy variable: $1=$ City with at least 10,000 inhabitants around 1290; $0=$ no city

Source: Campbell (2008)

Harbours in 1290

Dummy variable: $1=$ Important harbour around $1290,0=$ no important harbour

Source: Campbell (2008)

Limits to Agricultural Use

Dummy variable: $1=$ Limits to agricultural use due to characteristics of the soil (e.g. gravelly, lithic or sodic soil); $0=$ no limits

Source: The data are taken from the European Soil Project (Panagos et al., 2012; $1 \mathrm{~km}$ by $1 \mathrm{~km}$ raster data). The data generation procedure of Combes et al. (2010) was followed.

Soil Depth

Ordinal variable: Soil depth to rocks: $1=$ Shallow $(<40 \mathrm{~cm})$, $2=$ Moderate $(40-80 \mathrm{~cm}), 3=$ Deep $(80-120 \mathrm{~cm}), 4=$ Very deep $(>120 \mathrm{~cm})$ 
Table 1. (continued)

Variable Description and Source

Ruggedness

Population Density 1891

Ethnic Diversity Change 2001-2011

Unemployment Change 2001-2011

GVA per Capita Change 2001-2011
Source: The data are taken from the European Soil Project (Panagos et al., 2012; $1 \mathrm{~km}$ by $1 \mathrm{~km}$ raster data)

Difference between the maximum and minimum elevations in meters

Source: The data are taken from the European Soil Project (Panagos et al., 2012; $1 \mathrm{~km}$ by $1 \mathrm{~km}$ raster data)

Populace in British regions

Source: The population data come from the British Census in 1891. The data were downloaded from the ICEM Nestar webpage

Ethnic diversity in 2001 and 2011 were computed using the equation for a standard fractionalisation index $1-\sum_{i}\left(\text { Pop share of ethnic groups } \mathrm{s}_{\mathrm{i}}\right)^{2}$

where the $i$ different ethnic groups are Caucasian, Black, Asian and Mixed

The change in this index is calculated as difference between the 2011 and the 2001 index

Source: The population data regarding the different ethnicities in 2001 are taken from the 2001 census for England, Wales (ks201ew) and Scotland. The same applies to the 2011 data

Unemployment rates in 2001 and 2011 are computed by dividing the number of the unemployed by the sum of full-time and part-time employed populace. The change in this index is calculated as difference between the 2011 and 2001 unemployment rate

Source: The data are taken from the 2001 census for England, Wales and Scotland (ks009a). The same applies to the 2011 data

Source: Gross Value Added (income approach) per head data are taken from the ONS. The ONS provide data for 143 NUTS3 regions which were allocated to the LADs via GIS. Note that one NUTS3 region often consists of several LADs. As a consequence, these LADs will have the same GVA per head data. The change index is computed as the difference between the 2011 GVA per head and the 2001 GVA per head

England and Wales as well as the historic registration county level in Scotland and are assigned to contemporary LADs using Geographic Information Systems (GIS). Across Great Britain as a whole, the employment in these large-scale industries, representing historical industrialisation, is $19.2 \%$. However, this varies from $64.3 \%$ in Burnley in Lancashire to only $2.2 \%$ in Forest Heath in Suffolk.

\subsection{Coalfields as an instrumental variable}

To establish the direction of the effects, it is important to tackle potential endogeneity regarding the relationship between large-scale coal-based industries and the measures of community cultural practice. To do so, we employed the instrumental variable (IV) technique, an approach typically employed in economics (e.g. Nunn and Wantchekon, 2011) and also increasingly in psychology (Auger et al., 2014). The rationale behind the IV technique is to check for the directionality of hypothesised effects. For example, industrialisation (Ind) is hypothesised to affect community cultural practice (Cult); in other words, variation in Ind shall explain variation in Cult. However, if industry is attracted to 
localities displaying particular community cultural practices, it is possible that a reverse effect from Cult to Ind may be present. In that case, industrialisation (Ind) is endogenous. In a standard Ordinary Least Squares (OLS) regression setting, the econometric consequence of this endogenous relationship between Ind and Cult is that the variable Cult is correlated with the error term and, thus, a standard OLS regression cannot consistently measure the effect of Ind on Cult.

To overcome this potential endogeneity, we need to identify a third variable that is related to industrialisation (Ind), but has no theoretical links to community cultural practice (Cult). This study applies the same approach adopted by Glaeser et al. (2015) and Stuetzer et al. $(2016,2018)$ by utilising the minimum distance to the nearest coalfields as an exogenous instrument (CoalDist). Obschonka et al. (2017) indicate that the shorter the distance a region is to a coalfield (CoalDist), the lower the coal prices and, therefore, the higher the employment share in large-scale coal-based industries (Ind). To localise coalfields we digitized an historic map of coalfields from Hatcher $(1993,64)$ and computed the minimum distance of a locality to a coalfield by GIS.

As a first step, we use variation in distance to coalfields (CoalDist) to explain variation in industrialisation (Ind). In other words, we predict the employment share in large-scale coal-based industries (Ind ${ }^{\text {pred }}$ ) that can be explained by the spatial proximity to coalfields (CoalDist). This isolates the variation in industrialisation associated with distance from coalfields from the endogenous element associated with any reverse relationship from community cultural practice:

$$
\text { Ind }_{l}^{\text {Pred }}=\gamma_{0}+\gamma_{1} \text { CoalDist }_{l}+\gamma_{2} \text { Hist }_{l}+e_{l}^{\text {first }}
$$

In estimating the predicted employment large-scale industry for locality $(l)$ to represent historical industrialisation we also control for a variety of historical variables (Hist). These are discussed in more detail below.

As the second step of the IV analysis, this coal related employment share in large-scale coal-based industries ( $I n d^{\text {pred }}$ ) is used to explain the dimensions $(i)$ of community cultural practice that develop $\left(\mathrm{Cult}^{i}\right)$. This reflects the exogenous element of industrialisation, separated from any reversed relationship running from community cultural practice to industrialisation:

$$
\text { Cult }_{l}^{i}=\beta_{0}+\beta_{1} \text { Ind }_{l}^{\text {Pred }}+\beta_{2} \text { Hist }_{l}+e_{l}^{\text {second }}
$$

The community cultural practice variables $\left(C u l t^{i}\right)$ reflect the five dimensions discussed earlier and each is regressed on the predicted industrialisation along with the historical and contemporary controls.

\subsection{Historical control variables}

While an instrumental variable can clarify the direction of effects, control variables help rule out alternative explanations for observed effects. To control for additional historical factors potentially jointly affecting the localisation of large-scale industries and cultural characteristics of the regions, we consider a number of historical control variables (Oishi, 2014).

Energy supply: Industrialisation began earlier than the invention of the steam engine, and, therefore, it is possible that the seeds of industrial structure were already set before 
the age of steam. Besides horses, the most important power source in medieval times came from water mills. Thus, the number of water mills in British regions around 1800 serves as a control variable in the regressions. The number of water mills is taken from Kanefsky (1979), who build his data on very detailed historical county maps showing the location of these mills.

Market potential and historical wealth: To maximise market access, Crafts and Mulatu (2005) suggest that industries will locate in close proximity to their customers. This means that there would tend to be a concentration around larger and wealthier population centres. There may also be an influence on community culture arising from urban development, as this may have a direct effect on, or at least, start the type of selective migration processes discussed earlier. In the UK, many larger agglomerations such as Sheffield developed during the Industrial Revolution as a result of the presence of large-scale industries. However, not all urban development was as driven by the arrival of the Industrial Revolution to the same extent, a case in point being London. Furthermore, studies have regularly found urban areas to have different cultural, social, and economic trajectories from more rural areas (Oishi, 2014). In particular, studies have found differences associated with values relating to tolerance and individualism (Hofstede, 2001). In the case of the latter, this may reduce the desire for caring activities and collective activities. Consistent with Inglehart's (1971) work on acquisitive versus postbourgeois individuals, Peterson and van Iterson (2015) find that living in urban areas is associated with values associated with placing a greater emphasis on the fulfilment of the work itself (intrinsic rewards) and working with pleasant people (social rewards).

To account for these factors, we include a number of measures. Urbanisation is captured by the local population density (measured in the 1891 census). We additionally control for employment in 1891 as a Harris-type market potential function, which is computed as a distance-weighted sum of the employment levels of the region under investigation and all other regions (for a similar approach see Crafts and Mulatu, 2005). This variable is intended to reflect wealth and market potential.

More historical urban development is captured by a dummy variable reflecting the presence of a larger city in the Middle Ages (1290) (Campbell, 2008). This helps to identify those urban areas that were present prior to industrialisation and those that were formed as a consequence of industrialisation alone. This is of value as it is possible that where medieval cities existed as trading centres, guilds would control enterprise and limit the development of industrialisation when the Industrial Revolution arrived (Stuetzer et al., 2016). It is also possible that with other business opportunities absorbing local capital, large-scale industry may face greater competition for finance.

A final historical indicator for wealth is the presence of ports. In Great Britain, ports were hubs for domestic trade and also for trade with Continental Europe. Contact with other parts of the world may influence community culture, in particular social cohesion. Therefore, we include a dummy variable indicating the regional presence of a port in the middle ages (around 1290). The data regarding the location of ports is taken from Campbell (2008).

Geology: Research indicates that geology can shape local cultures (Oishi, 2014), via, for example, local differences in agrarian productivity or in historical trade (Greif, 1994). Therefore, we consider there is a need to add control variables to address this. Following Falck et al. (2012), we include the soil quality of a region with a dummy variable indicating any limits to agricultural use (e.g. gravelly, lithic or sodic soil). We additionally consider the soil depth to rocks, with larger values indicating more suitable soil for 
agriculture and thus pre-industrial wealth. These data are taken from the European Soil Project (Panagos et al., 2012; $1 \mathrm{~km}$ by $1 \mathrm{~km}$ raster data) and the data generation procedure is described in Combes et al. (2010). We also consider the ruggedness of a region. Historical trade routes connected economic centres but avoided difficult terrain such as mountains. Therefore, the ruggedness of a region is an acceptable indicator for terrain difficulty, which can also be understood as a proxy of low regional pre-industrialisation wealth generated by trade (Greif, 1994). Following others, we measure the ruggedness of a region by the difference between the maximum and minimum elevation (Falck et al., 2012). Data on terrain differences also come from the European Soil Project (Panagos et al., 2012).

\section{Results}

In Figure 2, the distance of an LAD to the nearest coalfield and the 1891 employment share in large-scale industries is visualised, while Figure 3 shows the regional distribution of the dimensions of community cultural practice. From these illustrations, it is clear to see the concentration of late nineteenth-century large-scale industry in close proximity to the coalfields in the Scottish Central Belt, South Wales Valleys, North East of England and parts of the North West, Yorkshire and Humber, East Midlands and West Midlands. Visually, there also appears to be a degree of correspondence between these areas where large-scale industry accounted for a greater share of employment in 1891 and the dimensions of cultural practice. In general, these areas display community cultural practices with lower engagement with education and employment (particularly Wales and Scotland); greater social cohesion (South Wales Valleys, West Midlands and Scottish Central Belt); more feminine and caring activities (North West, East Midlands and West Midlands); low adherence to social rules (Yorkshire and Humber, North West, South Wales Valleys and Scottish Central Belt); and greater collective action (North East, Wales and Scotland). Despite these visual hints, it is not clear whether any statistical relationship will be present between historical industrialisation and contemporary cultural practices, especially after controlling for other influences. In a robustness check, we additionally rely on three contemporary controls: 1) ethnic diversity change, 2) unemployment change, and 3) Gross Value Added (GVA) change where change refers to the period from 2001 to 2011.

To address these relationships, Model 1 of Table 3 shows the first-stage regression of employment in large-scale industry in 1891 on the distance from coalfields and other historic controls. As all non-binary and non-ordinal variables are logged, the coefficients can be interpreted as elasticities. Given the reliance of large-scale industry on steam power, the distance from coalfields is negatively and significantly related to the share of employment in large-scale industries (Crafts and Mulatu, 2005; Crafts and Wolf, 2014; Stuetzer et al., 2016). The first-stage $F$-statistic is well above 10 indicating the relevance of the instrument. There is also a slight negative relationship found with the market potential in 1891 , but a positive relationship with the population density of the same region. The size of the coefficients indicates a $1 \%$ change in distance from coalfields has an impact on employment in large-scale industry roughly three times the size of the same $1 \%$ change in population density. Together, this suggests that the localisation of large-scale industries was mostly driven by the availability of cheap coal instead of large consumer markets.

Models 2-5 present the estimation results regressing the dimensions of community cultural practice on industrialisation and other historical controls. We consider each of the 


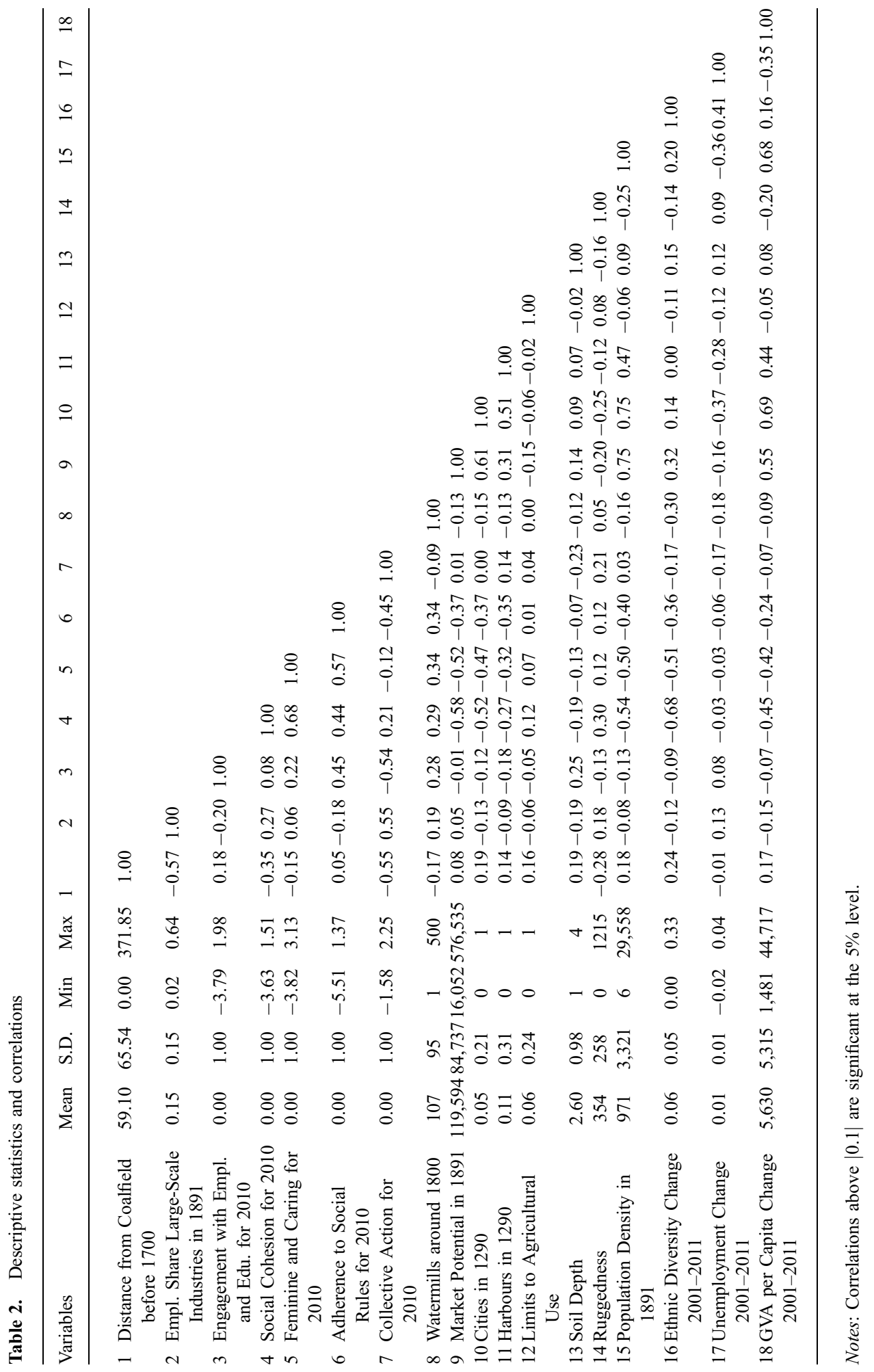



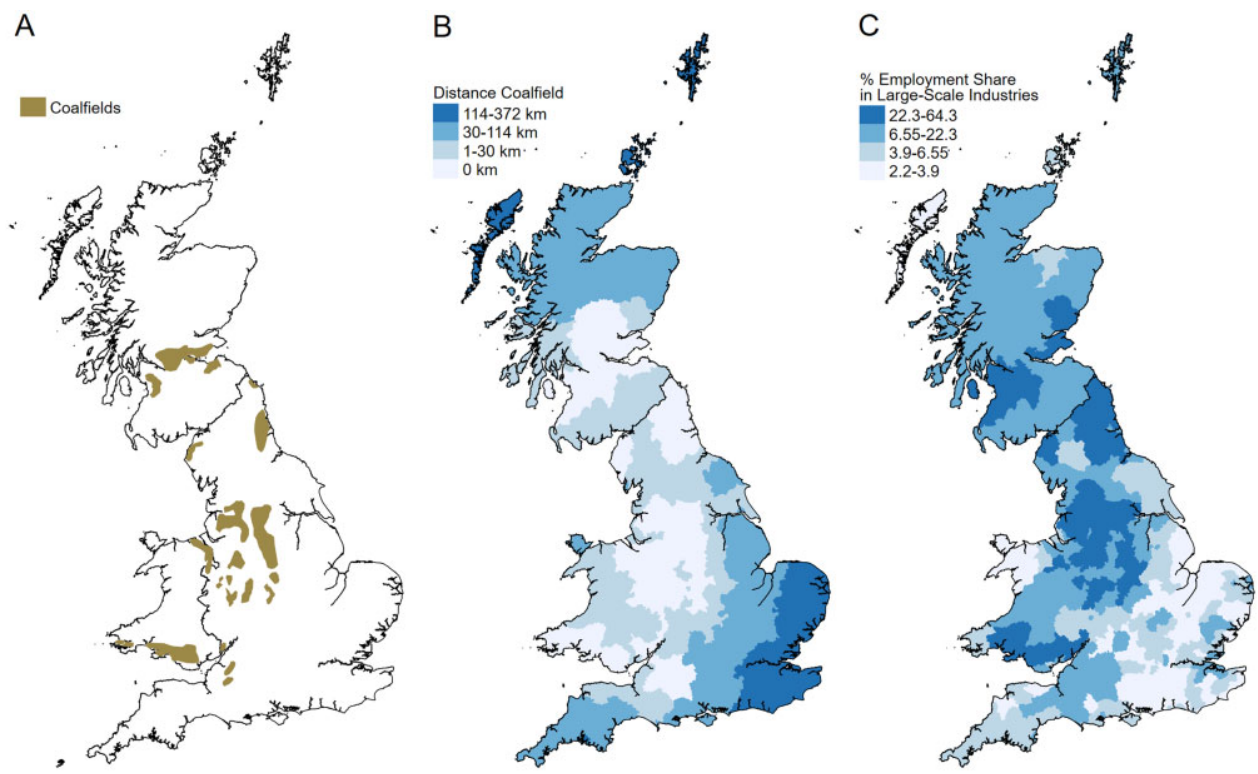

Figure 2. Coalfields, distance from an LAD to the nearest coalfield and industrialisation.

dimensions of community cultural practice in turn, starting with engagement in education and employment (Model 2). Employment in large-scale industries displays a negative and significant relationship with engagement with education and employment. This supports Hypothesis $H 1$ whereby historical industrialisation reduces social mobility and encourages a greater reliance on others (Gylfason, 2001; Zijdeman, 2009; Matthews and Gallo, 2011), and lowers contemporary community cultural practices associated with engagement in education and employment.

Evidence of this impact from industrialisation on engagement with education and employment can be found in the coal mining areas of south Wales and the central belt of Scotland associated with shipbuilding, but it is less apparent in many of the textile and steel areas of Lancashire and Yorkshire. In terms of the historical controls, significant positive relationships are also found for market potential and earlier smaller scale industrial development in the form of water mills, which is consistent with the potential for reward and social advancement having a lasting impact on this dimension of community cultural practice. Such advancement ameliorates the need to concentrate on issues of survival, which is consistent with the soil depth's positive relationship to engagement with education and employment where pre-industrial productivity would be higher (Combes et al., 2010). However, after controlling for market potential, population density may hinder social advancement for many due to increased competition leading to a negative relationship.

Industrial employment is positively associated with social cohesion (Model 3 in Table 3), and this fits with the positive hypothesised relationship $H 2$ between historical industrialisation and the social cohesion dimension of community cultural practices. This relationship may reflect the paternalistic nature of large-scale employers creating a sense of togetherness (Tranter, 1988; Thompson, 2008), but also the self-selecting migration occurring when traditional industries declined (Obschonka et al., 2017). The presence of early 

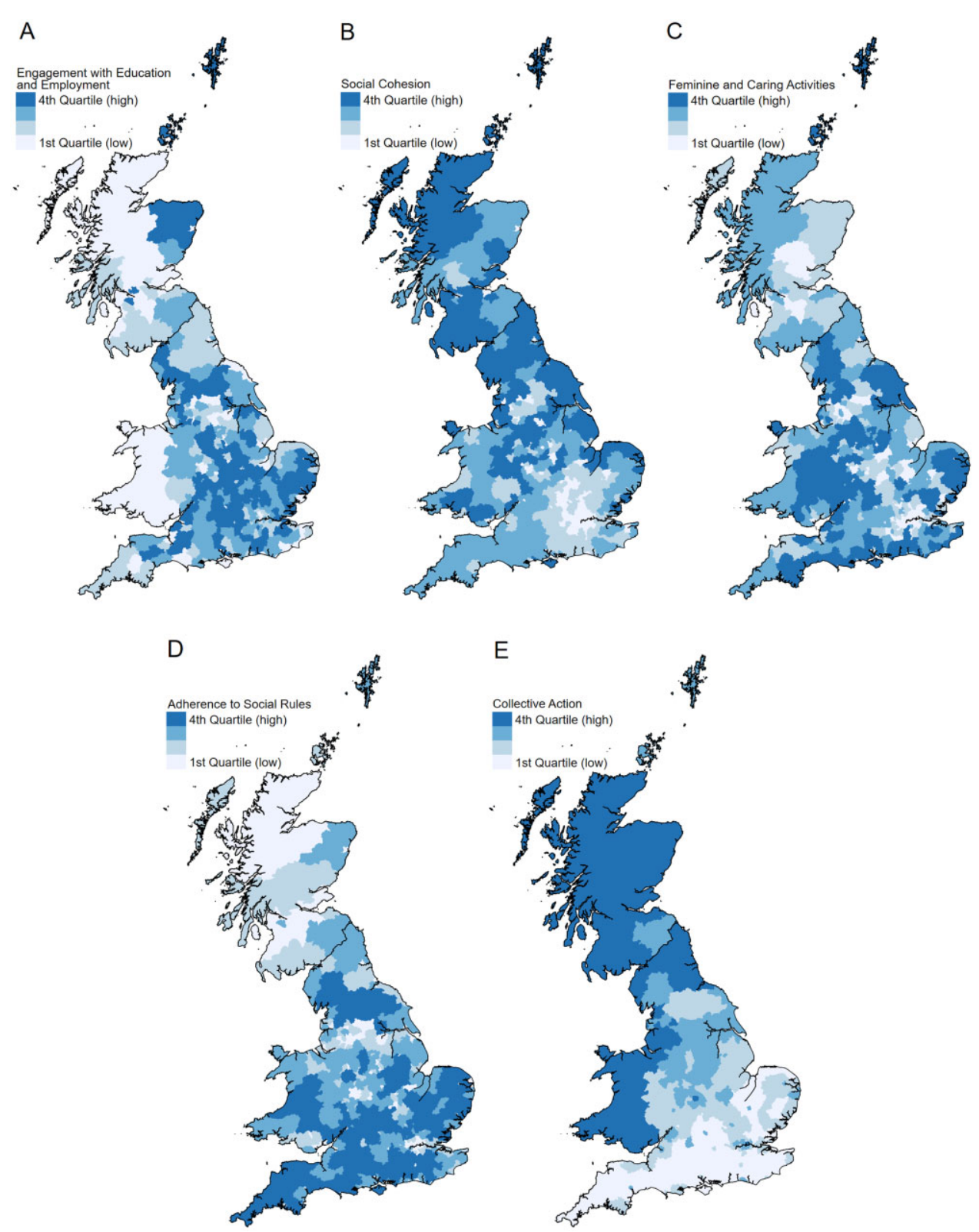

Figure 3. Community cultural practices.

industrialisation through water power also has a positive effect, although the coefficient is considerably smaller in size.

Other significant control variables appear to support the self-selecting migration argument with market potential and population density reducing social cohesion as more ambitious and entrepreneurial members of the population are drawn to urban centres from more rural locations, which retain less mobile individuals (Casson, 1995). Ruggedness is also 


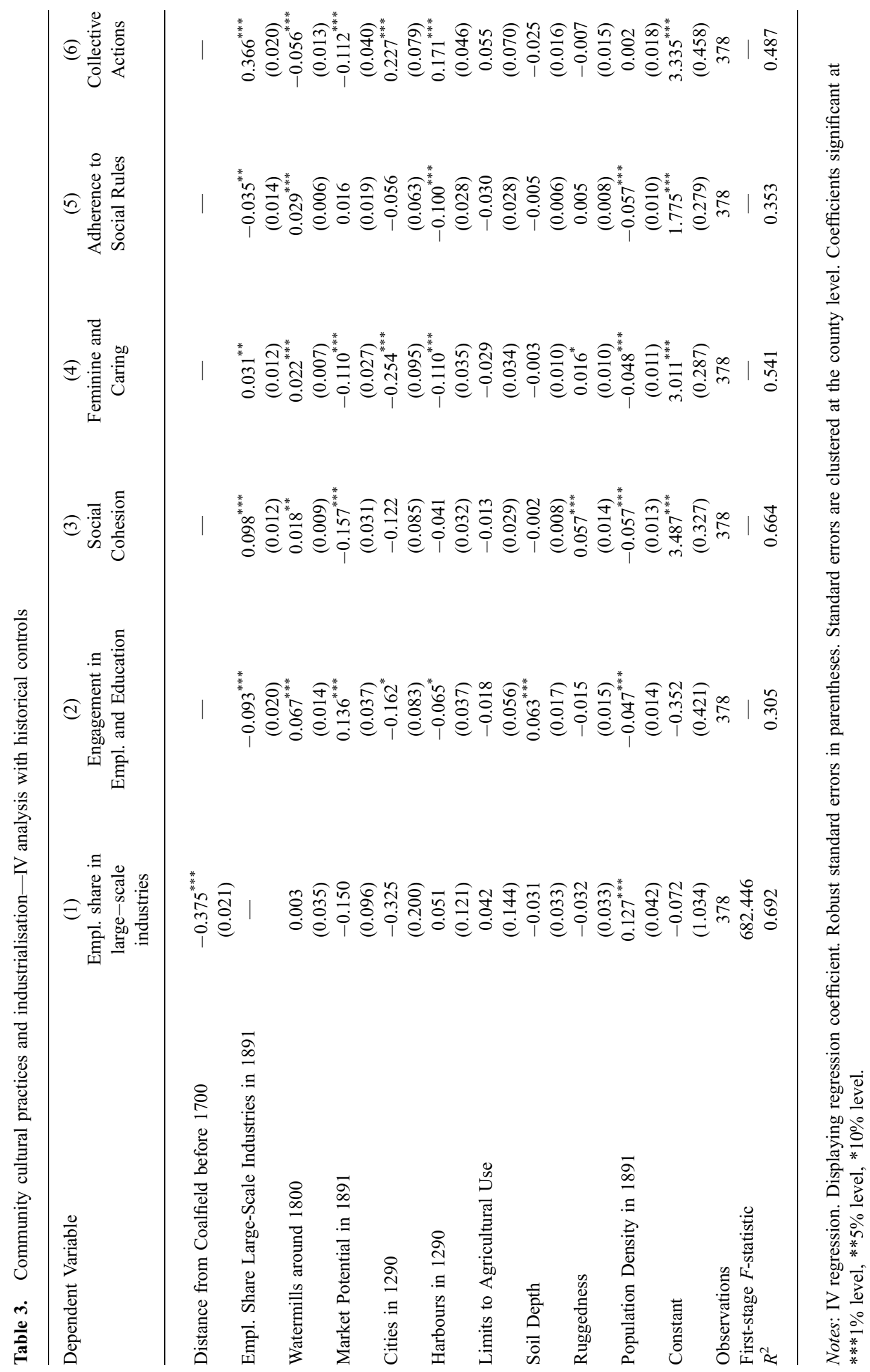


positively associated with social cohesion, which makes sense where the harsh nature of living in more mountainous areas increases the interdependence of the population.

There is a positive but weaker relationship between industrial employment and feminine and caring activities (Model 4). This is consistent with Hypothesis H3, which from the literature suggests that the physical and arduous nature of employment in much large-scale industry led to work regarded as masculine in nature being promoted (Hudson, 1994; Duncan and Smith, 2002), and a home-based and family orientated role imposed on women (Sackmann and Häussermann, 1994).

One explanation for the weaker relationship found between historic industrialisation and feminine and caring activities, in contrast to social cohesion for example, may relate to evidence suggesting that such a pattern is less apparent in the textile industry, which employed large numbers of women (Glucksmann, 2000; Duncan and Smith, 2002). Interestingly, it appears that only large-scale industrial development, and its forerunner in terms of water power, has a positive relationship with feminine and caring activities as early centres of trade, such as medieval cities and harbours with longer traditions of market economies and densely populated areas with greater market potential, all of which have negative relationships with such community cultural practices. Ruggedness is positively associated with feminine and caring activities, as it was with social cohesion, reflecting the need to depend on others in harsher environments.

A negative relationship between industrial employment and adherence to social rules is found (Model 5); which appears strongly in the coal mining areas of Yorkshire and Humber, the South Wales Valleys, plus the central belt in Scotland. These are all areas that have suffered from economic decline and deprivation and associated rises in antisocial behaviour and falling trust (Alesina and La Ferra, 2000; Power et al., 2010). Combined with limited autonomy and the repetitiveness of employment that reduced selfdirection (Kohn and Schooler, 1982; Acemoglu, 2002), this was hypothesised (H4) to produce a negative relationship between historical industrialisation and adherence to social rules. The potentially transient population of harbour areas also appear to have weakened such adherence to rules, having a negative effect in Model 5. Smaller scale industry associated with water power does not seem to have the same negative impact on adherence to social rules.

Lastly a positive effect for historical industrialisation is found for collective action (Model 6 in Table 3). Across the UK, this shows up strongly in Wales and Scotland as well as the Lancashire textile areas and steel manufacturing areas of the North East. To a lesser degree, this relationship is also found in Yorkshire and Humber and the East Midlands coalfields in Nottinghamshire and Derbyshire. This supports Hypothesis H5 which suggests that large-scale production encourages the development and influence of unions both within these industries and more broadly in the local economy and society (Sadler and Thompson, 2001; Holmes, 2006). As well as this sizeable effect from historic industrialisation, collective action is also associated with the historical trade centres of early cities and harbours, where more skilled craftsmen are likely to have gathered. The smaller scale production associated with water power potentially leads to a different type of development with less opportunity for labour unions to form.

Taken together the results presented in Table 3 indicate that historic industrialisation affects all our five community cultural practice dimensions. This is found to be the case when using coalfields to instrument for historic industrialisation to account for potential endogeneity in the development of large-scale industry. This relationship appears to be strongest for collective action (Hypothesis H5) where concerns about the unfair 
distribution of returns from exploiting mineral wealth and the efforts of labour (Alesina and Angeletos, 2005), along with greater unionisation (Holmes, 2006), have had a lasting impact on this dimension of community cultural practice.

Although having an impact roughly a third of the size as for collective action, historic industrialisation appears to have increased social cohesion and reduced engagement with education and employment. These are hypothesised to be artefacts of the self-selecting migration occurring with the decline of traditional industries (Obschonka et al., 2017), resulting in a more tightly bonded population (Hypothesis $H 2$ ); and limited social mobility that reduces the incentive to invest in human capital (Hypothesis H1). These collectively orientated, tightly bonded areas with restricted human capital appear to be the products of their historical development, with the community cultural practices established having the result of limiting their opportunities to generate new development paths.

In the remainder of the section, we discuss robustness checks, the tables of which are included in the Supplementary Appendix. When comparing the IV estimation results in Table 3 with simple OLS regression (Supplementary Appendix A2), it should be noted that the size of the coefficient of industrialisation does not differ much with the exception of the dependent variable engagement with education and employment. Here the IV coefficient is moderately smaller than the OLS coefficient (Model 2 in Table 3 and Model 1 in Supplementary Appendix Table A2), which could be explained by public programmes retraining the population and active labour market policies that were implemented in the twentieth century in old industrial regions - and are not picked up by the IV regression (Birch et al., 2010).

To further check robustness, we include additional contemporary controls to rule out the possibility that contemporary factors, and not our historical industrialisation variable, are the main determinants of contemporary community cultural practice measures. A similar approach was conducted by Stuetzer et al. (2016). The respective results are presented in the Supplementary Appendices (Table A3 with IV regressions and Table A4 with OLS regressions). Most results are very similar, with the only notable difference being that industrialisation does not predict feminine and caring activities when including contemporary controls (Model 4 in Supplementary Appendix Table A3). Therefore, we conclude that our hypotheses can be supported, with the exception of Hypothesis $H 3$ which is weaker and not robust to the inclusion of contemporary controls. As discussed previously, the impact of large-scale production on the separation of work and home is not necessarily identical for all industries (Duncan and Smith, 2002), and can vary between areas even for the same industries if the traditions of production differ (Sackmann and Häussermann, 1994). Some of this latter effect may be captured by contemporary controls, particularly growth in GVA, where rising prosperity is likely to encourage mothers back into the workforce, and particularly where traditions of female employment were strong.

A further robustness check deals with spatial auto-correlation. Cultural characteristics in a region can depend on characteristics from nearby regions due to spillover effects. This might be especially relevant for our approach as we use the fine-grained LAD level in the analysis. Therefore, we rerun the analysis with spatial lags on the independent variables using the normalised inverse of the squared distances between regions. However, if we truly believe in the local nature of cultural practice formation, we anticipate that the characteristics of nearby localities do not matter much compared to the characteristics of the locality under investigation. The results of the reduced form estimation with spatial lags are shown in Supplementary Appendix Table A5 and confirm our expectation. 
We also rerun the regression at the coarser level of counties. The IV regression results with the historic controls are presented in Supplementary Appendix Table A6, and adding the contemporary controls are presented in Supplementary Appendix Table A7. The spatial regressions at the county level are depicted in Supplementary Appendix Table A8. All these robustness checks confirm that employment in large-scale industries negatively impact on engagement in education and employment (Hypothesis H1) and adherence to social rules (Hypothesis H4), but positively with social cohesion (Hypothesis H2) and collective action (Hypothesis H5), whereas the support regarding feminine and caring activities is mixed (Hypothesis $H 3$ ).

\section{Discussion and conclusions}

The results of the regressions reveal the long-lasting imprint of industrialisation as measured by employment in large-scale industries on contemporary culture. This is likely to have lasting consequences for the current development paths available for these localities given the potential to influence cognitive lock-in and the strong connections between regional and industrial culture (Cooke and Rehfeld, 2011). In particular, it was found that communities that were previously exposed to greater changes through industrialisation, today have less engagement with education and employment, stronger social cohesion, adhere less to social rules and are more oriented towards collective action. The existing literature indicates that not one, but a number of mechanisms - as summarised in Figure 1-may link historical industrialisation to community cultural practices. Although all mechanisms found some support, the magnitude of the coefficients suggest that limited social mobility, selective migration and unionisation play substantial roles.

The results regarding the effect of large-scale employment on social cohesion and collective action relate well to arguments concerning the negative effects of such an industry structure on entrepreneurship, innovation and growth (Glaeser et al., 2015; Stuetzer et al., 2016, 2018). In such communities, members tend to come to rely more heavily on strong ties within the community than on weak ties (outside their communities). It is also possible that within these areas communities are associated with particular employers that are tightly bonded together, which may have an aversion to spatially wider collaboration and knowledge exchange. Tödtling and Trippl (2004) highlight the extent to which overcoming strong ties to produce more bridging connections both within and without clusters in the Austrian region of Styria explain the differing trajectories of these clusters. Without the knowledge flows necessary for innovative and entrepreneurial activities there are negative long-term effects on regional economic development (Huggins and Thompson, 2016). Specifically, the potentially resulting cognitive and political lock-in is one of the factors that influences the adaptability of old industrial regions, and differentiates between those able to accommodate shocks and structural change and those that struggle to do this $(\mathrm{Hu}$ and Hassink, 2016). Our findings regarding the effect of industrialisation on adherence to social rules can be related to the larger literature on trust. In particular, communities in which social rules are not adhered to may suffer from weaker trust between community members, and result in reduced economic growth (Zak and Knack, 2001).

We also found a negative relationship between industrialisation and engagement with education and employment. This is of practical importance as policies looking to rejuvenate deprived areas have frequently sought to boost the human capital of the population and promote entrepreneurship (Birch et al., 2010). Industrialisation may have left a lasting 
legacy manifested by lower levels of engagement with education and employment that undermines the effectiveness of these programmes. Where, for example, large-scale low skill foreign direct investments (FDIs) are sought and incentivised, it may even perpetuate the problem. Those providing support to such localities and regions need, therefore, to be highly aware of the existing culture and its relationship to this support, i.e. utilising strengths in social cohesion and feminine and caring activities, such as supporting community enterprises and community energy initiatives. However, they must also consider the longer-run consequences. Will a greater reliance on the community's own resources result in future social cohesion reaching a point that excludes the community from wider knowledge flows? If so, can a more holistic approach draw on other bodies and institutions, such as local universities, with their wider networks counter this?

The study suggests a number of directions for future research. The measures of community cultural practice used here allow an investigation at the local level. However, they are not without criticism and ideally the study should be replicated with alternatives that more directly measure community culture. Unfortunately, current alternative cultural measures based largely on survey data do not allow such spatially disaggregated investigation. Given the likely impact of a variety of factors on community culture, and community culture itself on economic development, the value in being able to tailor policy support appropriately means that a regularly collected measurement of community culture and other associated variables, such as personality, would be extremely valuable for policy making.

Our research on the deep, long-lasting cultural imprint of industrialisation makes several contributions to different streams of economic geography. Regarding evolutionary economic geography, our results suggest that organisational routines in large-scale industries shape the regional culture. Also, to the extent that there are feedback effects from culture on organisational routines, regional and local cultures are likely to be one means by which specific organisational routines can be transferred over time within particular spaces - even if they hinder rather than facilitate economic performance and development. As discussed, this means that community culture can be a source of cognitive lock-in limiting the potential of old industrial areas to adapt to global forces. This indicates that historic industrialisation has both been a source of success but through the mechanisms outlined in this study has also left a lasting imprint that in some regards may have resulted in a greater cost than the original benefits.

Our results on the lasting effect on social cohesion and collective action inform relational economic geography, which emphasises the embeddedness of regional actors. Not only are economic actions embedded and based in structures of social relations (Bathelt and Glückler, 2003), but economic history can also shape the structure of these relations (in our case towards more social cohesion and collective action). Finally, from the perspective of institutional economic geography, the empirical evidence provided by this study suggests that informal institutions can persist over a long period of time even when the initial determinant of these institutions - in this case, the emergence of large-scale firms based on the availability of nearby 'cheap' coal-has long since vanished. As such community culture can be seen as a key conceptual feature that helps to connect different perspectives examining regional development (Huggins and Thompson, 2019; 2021). Future work is advised to more fully and explicitly incorporate the mechanisms identified here as a means of establishing an increasingly integrated view of the common but often hidden causal elements of such development across differing perspectives. 


\section{Supplementary material}

Supplementary data for this article are available at Journal of Economic Geography online.

\section{References}

Acemoglu, D. (2002) Technology and the labour market. Journal of Economic Literature, 40: 7-72.

Aldcroft, D. H., Oliver, M. J. (2017) Trade Unions and the Economy: 1870-2000. Abingdon: Routledge.

Alesina, A., Angeletos, G.-M. (2005) Fairness and redistribution. American Economic Review, 95: 960-980.

Alesina, A., Giuliano, P. (2015) Culture and institutions. Journal of Economic Literature, 53: 898-944.

Alesina, A., La Ferra, E. (2000) The determinants of trust. NBER Working Paper No. 7621, NBER.

Auger, A., Farkas, G., Burchinal, M. R., Duncan, G. J., Vandell, D. L. (2014) Preschool center care quality effects on academic achievement: An instrumental variables analysis. Developmental Psychology, 50: 2559-2571.

Bathelt, H., Glückler, J. (2003) Toward a relational economic geography. Journal of Economic Geography, 3: 117-144.

Becattini, G. (2015) Beyond geo-sectoriality: the productive chorality of places. Investigaciones Regionales: Journal of Regional Research, 32: 31-41.

Becker, S. O., Woessmann, L. (2009) Was Weber wrong? A human capital theory of Protestant economic history. Quarterly Journal of Economics, 124: 531-596.

Birch, K., MacKinnon, D., Cumbers, A. (2010) Old industrial regions in Europe: a comparative assessment of economic performance. Regional Studies, 44: 35-53.

Blažek, J., Květoň, V., Baumgartinger-Seiringer, S., Trippl, M. (2020) The dark side of regional industrial path development: towards a typology of trajectories of decline. European Planning Studies, 28: 1455-1473.

Campbell, B. M. S. (2008) Benchmarking medieval economic development: England, Wales, Scotland, and Ireland, c.1290. Economic History Review, 61: 896-945.

Carter, S., Marlow, S., Bennett, D. (2012) Gender and entrepreneurship. In S. Carter and D. Jones-Evans (eds) Enterprise and Small Business: Principles, Practice and Policy, pp. 2018-2031. London: Pearson.

Casson, M. (1995) Entrepreneurship and Business Culture: Studies in the Economics of Trust, vol. 1. Aldershot: Edward Elgar.

Coenen, L., Moodysson, J., Martin, H. (2015) Path renewal in old industrial regions: possibilities and limitations for regional innovation policy. Regional Studies, 49: 850-865.

Cooke, P., Rehfeld, D. (2011) Path dependence and new paths in regional evolution: in search of the role of culture. European Planning Studies, 19: 1909-1929.

Combes, P.-P., Duranton, G., Gobillon, L., Roux, S. (2010) Estimating agglomeration economies with history, geology and worker efforts. In E. L. Glaeser (ed) The Economics of Agglomeration, pp. 15-66. Chicago and London: University of Chicago Press.

Couttenier, M., Sangier, M. (2015) Living in the Garden of Eden: mineral resources and preferences for redistribution. Journal of Comparative Economics, 43: 243-256.

Crafts, N., Mulatu, A. (2005) What explains the location of industry in Britain, 1871-1931? Journal of Economic Geography, 5: 499-518.

Crafts, N., Wolf, N. (2014) The location of the UK cotton textiles industry in 1838: a quantitative analysis. Journal of Economic History, 74: 1103-1139.

Di Tella, R., Dubra, J., MacCulloch, R. (2010) A resource belief-curse? Oil and individualism. In W. Hogan and F. Stursenegger (ed) The Natural Resources Trap: Private Investment without Public Commitment, pp. 119-154. Cambridge, MA: MIT Press.

Duncan, S., Smith, D. (2002) Geographies of family formations: spatial differences and gender cultures in Britain. Transactions of the Institute of British Geographers, 27: 471-493.

Durkheim, E. (1893) The Division of Labour in Society. New York, NY: Macmillan. 
Falck, O., Heblich, S., Lameli, A., Südekum, J. (2012) Dialects, cultural identity, and economic exchange. Journal of Urban Economics, 72: 225-239.

Flanagan, S. C. (1982) Changing values in advanced industrial societies: Inglehart's silent revolution from the perspective of Japanese findings. Comparative Political Studies, 14: 403-444.

Fukumoto, I. K., Grusky, D. B. (1993) Social mobility and class structure in early-industrial France. In A. Miles and D. Vincent (eds) Building European Society: Occupational Change and Social Mobility in Europe, 1840-1940, pp. 40-67. Manchester: Manchester University Press.

Gertler, M. S. (2001) Manufacturing Culture: The Institutional Geography of Industrial Practice. Oxford: Oxford University Press.

Glaeser, E. L., Kerr, S. P., Kerr, W. R. (2015) Entrepreneurship and urban growth: an empirical assessment with historical mines. Review of Economics and Statistics, 97: 498-520.

Glucksmann, M. (2000) Cottons and Casuals: The Gendered Organisation of Labour in Space and Time. Durham: Sociology Press.

Görmar, F., Harfst, J. (2019) Path renewal or path dependence? The role of industrial culture in regional restructuring. Urban Science, 3: Article 106.

Greif, A. (1994) Cultural beliefs and the organization of society: a historical and theoretical reflection on collectivist and individualist societies. Journal of Political Economy, 102: 912-950.

Guiso, L., Sapienza, P., Zingales L. (2006) Does culture affect economic outcomes? Journal of Economic Perspectives, 20: 23-48.

Gylfason, T. (2001) Natural resources, education, and economic development. European Economic Review, 45: 847-859.

Hassink, R. (2010) Locked in decline? On the role of regional lock-ins in old industrial areas. In R. Boschma and R. Martin (eds) Handbook of Evolutionary Economic Geography, pp. 450-468. Cheltenham: Edward Elgar.

Hassink, R., Gong, H. (2017) Sketching the contours of an integrative paradigm of economic geography. Lund University Papers in Innovation Studies 2017/12. Lund: Centre for Innovation, Research and Competence in the Learning Economy (CIRCLE), Lund University.

Hatcher, J. (1993) The History of the British Coal Industry: Volume 1 before 1700: Towards the Age of Coal. Oxford: Clarendon Press.

Hester, L. K., Fuller, J. B., Jr. (2001) Building union commitment: the impact of parental attitudes and participation. Labor Studies Journal, 26: 17-30.

Hofstede, G. (1980) Culture's Consequences: Internal Differences in Work Related Values. Beverly Hills, CA: Sage.

Hofstede, G. (2001) Culture's Consequences: International Differences in Work Related Values, 2nd ed. Thousand Oaks, CA: Sage.

House, R. J., Hanges, P. J., Javidan, M., Dorfman, P. W., Gupta, V. (2004) Culture, Leadership and Organizations: The GLOBE Study of 62 Societies. Thousand Oaks, CA: Sage.

Holmes, T. J. (2006) Geographic Spillover of Unionism, Working Paper 12025. Cambridge, MA: National Bureau of Economic Research.

$\mathrm{Hu}, \mathrm{X}$., Hassink, R. (2016) Explaining differences in the adaptability of old industrial areas. In U. Hilpert (ed) Routledge Handbook of Politics and Technology, pp. 162-172. New York, NY: Routledge.

Hudson, R. (1994) Institutional change, cultural transformation and economic regeneration: myths and realities from Europe's old industrial areas. In A. Amin and N. Thrift (eds) Globalization, Institutions, and Regional Development in Europe, pp. 196-216. Oxford: Oxford University Press.

Hudson, R. (2005) Re-thinking change in old industrial regions: reflecting on the experiences of North East England. Environment and Planning A, 37: 581-596.

Huggins, R., Thompson, P. (2016) Socio-spatial culture and entrepreneurship: some theoretical and empirical observations. Economic Geography, 92: 269-300.

Huggins, R., Thompson, P. (2019) The behavioural foundations of urban and regional development: culture, psychology and agency. Journal of Economic Geography, 19: 121-146.

Huggins, R., Thompson, P. (2021) A Behavioural Theory of Economic Development: The Uneven Evolution of Cities and Regions. Oxford: Oxford University Press.

Inglehart, R. (1971) The silent revolution in Europe: intergenerational change in six countries. American Political Science Review, 65: 991-1017.

Inglehart, R., Baker, W. E. (2000) Modernization, cultural change, and the persistence of traditional values. American Sociological Review, 65: 19-51. 
Jokela, M. (2009) Personality predicts migration within and between U.S. states. Journal of Research in Personality, 43: 79-83.

Kaasa, A., Vadi, M., Varblane, U. (2013) European Social Survey as a source of new cultural dimensions estimates for regions. International Journal of Cross Cultural Management, 13: 137-157.

Kanefsky, J. W. (1979) The Diffusion of Power Technology in British Industry 1760-1870. PhD dissertation, Faculty of Social Studies, University of Exeter.

Kohn, M. L., Schooler, C. (1982) Job conditions and personality: a longitudinal assessment of their reciprocal effects. American Journal of Sociology, 87: 1257-1286.

Kwon, S. W., Adler, P. S. (2014) Social capital: maturation of a field of research. Academy of Management Review, 39: 412-422.

Lorenzen, M. (2007) Social capital and localised learning: proximity and place in technological and institutional dynamics. Urban Studies, 44: 799-817.

Luster, T., Rhoades, K., Haas, B. (1989) The relation between parental values and parenting behaviour: a test of the Kohn hypothesis. Journal of Marriage and Family, 51: 139-147.

MacKinnon, D., Dawley, S., Pike A., Cumbers A. (2019) Rethinking path creation: a geographical political economy approach. Economic Geography, 95: 113-135.

Marx, K. 1859. [1979]. A Contribution to the Critique of Political Economy. New York, NY: International Publishers.

Massey, D. (1984) Spatial Division of Labour: Social Structures and the Geography of Production. London: Macmillan.

Matthews, K. A., Gallo, L. C. (2011) Psychological perspectives on pathways linking socioeconomic status and physical health. Annual Review of Psychology, 62: 501-530.

McSweeney, B. (2002) Hofstede's model of national cultural differences and their consequences: a triumph of faith - a failure of analysis. Human Relations, 55: 89-118.

Nunn, N., Wantchekon, L. (2011) The slave trade and the origins of mistrust in Africa. American Economic Review, 101: 3221-3252.

Obschonka, M., Stuetzer, M., Rentfrow, P. J., Shaw-Taylor, L., Satchell, M., Silbereisen, R. K., Potter, J., Gosling, S. D. (2018) In the shadow of coal: how large scale industries contributed to present-day regional differences in personality and well-being. Journal of Personality and Social Psychology, 115(5), 903-927.

Oishi, S. (2014) Socioecological psychology. Annual Review of Psychology, 65: 581-609.

Panagos, P., Van Liedekerke, M., Jones, A., Montanarella, L. (2012) Response to European policy support and public data requirements. Land Use Policy, 29: 329-338.

Peterson, M. F., van Iterson, A. (2015) Differences in work goals among regions of the Netherlands and Germany: functional, institutional and critical event influences. International Journal of Human Resource Management, 26: 277-297.

Piketty, T. (1995) Social mobility and redistributive politics. Quarterly Journal of Economics, 110: 551-584.

Piketty, T. (2014) Capital in the 21st Century. Cambridge, MA: Harvard University Press.

Power, A., Plöger, J., Winkler, A. (2010) Phoenix Cities. Bristol: Policy Press.

Rodríguez-Pose, A. (2001) Local production systems and economic performance in Britain, France, Germany, and Italy. In C. Crouch, P. Le Galès, C. Trigilia, and H. Voelzkow (eds) Local Production Systems in Europe. Rise or Demise?, pp. 25-45. Oxford: Oxford University Press.

Rodríguez-Pose, A. (2018) The revenge of the places that don't matter (and what to do about it). Cambridge Journal of Regions, Economy and Society, 11: 189-209.

Rodríguez-Pose, A., Hardy, D. (2015) Cultural diversity and entrepreneurship in England and Wales. Environment and Planning A, 47: 392-411.

Rodríguez-Pose, A., Storper, M. (2006) Better rules or stronger communities? On the social foundations of institutional change and its economic effects. Economic Geography, 52: 1-25.

Sackmann, R., Häussermann, H. (1994) Do regions matter? Regional differences in female labour-market participation in Germany. Environment and Planning A, 26: 1377-1396.

Sadler D.,, Thompson J. (2001) In search of regional industrial culture: the role of labour organisations in old industrial regions. Antipode, 33: 660-686.

Shneor, R., Metin Camgöz, S., Bayhan Karapinar, P. (2013) The interaction between culture and sex in the formation of entrepreneurial intentions. Entrepreneurship and Regional Development, 25: 781-803. 
Smith, A. 1776 [1977]. An Inquiry into the Nature and Causes of the Wealth of Nations. Edwin Cannan's annotated edition; Volume 1: Liv, 524; Volume II: 568.

Spence, J. T., Helmreich, R. L. (1978) Masculinity and Femininity: Theory Psychological Dimensions. Correlates, and Antecedents. Austin, TX: University of Texas Press.

Spigel, B. (2017) Bourdieu, culture, and the economic geography of practice: entrepreneurial mentorship in Ottawa and Waterloo, Canada. Journal of Economic Geography, 17: 287-310.

Stephan, U., Pathak, S. (2016) Beyond cultural values? Cultural leadership ideals and entrepreneurship. Journal of Business Venturing, 31: 505-523.

Storper, M. (2008) Community and economics. In A. Amin and J. Roberts (eds) Community, Economic Creativity and Organization, pp. 37-68. Oxford: Oxford University Press.

Stuetzer, M., Audretsch, D. B., Obschonka, M., Gosling, S. D., Rentfrow, P. J., Potter, J. (2018) Entrepreneurship culture, knowledge spillovers, and the growth of regions. Regional Studies, 52: 608-618.

Stuetzer, M., Obschonka, M., Audretsch, D. B., Wyrwich, M., Rentfrow, P. J., Coombes, M., ShawTaylor, L., Satchell, M. (2016) Industry structure, entrepreneurship, and culture: an empirical analysis using historical coalfields. European Economic Review, 86: 52-72.

Tabellini, G. (2010) Culture and institutions: economic development in the regions of Europe. Journal of the European Economic Association, 8: 677-716.

Thompson, F. M. L. (1981) Social control in Victorian Britain. Economic History Review, 34: 189-208.

Thompson, S. (2008) From paternalism to industrial welfare: The evolution of industrial welfare capitalism in the South Wales coalfield. Paper presented at Annual Conference of the Economic History Society, University of Nottingham, March 30, 2008, Available at: www.ehs.org.uk/ehs/.../ Assets/ThompsonSFullPaper.doc [Accessed 5 June 2018]

Tödtling F.,, Trippl M. (2001) Like phoenix from the Ashes? The renewal of clusters in old industrial areas. Urban Studies, 41: 1175-1195.

Tranter, N. (1988) Sport, Economy and Society in Britain 1750-1914. Cambridge: Cambridge University Press.

Triandis, H. C. (1993) Collectivism and individualism as cultural syndromes. Cross-Cultural Research, 27: 155-180.

Weber, M. 1905. [2001]. The Protestant Ethic and the Spirit of Capitalism. London: Routledge.

Weiner, M. (ed). (1966) Modernization: The Dynamics of Growth. New York, NY: Basic Books.

Wennberg, K., Pathak, S., Autio, E. (2013) How culture moulds the effects of self-efficacy and fear of failure on entrepreneurship. Entrepreneurship and Regional Development, 25: 756-780.

Whitbeck, L. B., Simons, R. L., Conger, R. D., Wickrama, K. A. S., Ackley, K. A., Elder, G. H. Jr. (1997) The effects of parents' working conditions and family economic hardship on parenting behaviors and children's self-efficacy. Social Psychology Quarterly, 60: 291-303.

Zak, P. J., Knack, S. (2001) Trust and growth. The Economic Journal, 111: 295-321.

Zijdeman, R. L. (2009) Like my father before me: intergenerational occupational status transfer during industrialization (Zeeland, 1811-1915). Continuity and Change, 24: 455-486. 